\title{
Component Reliability
}

Electronic

Engineering Series

울

Macmillan

Engineering Evaluations 


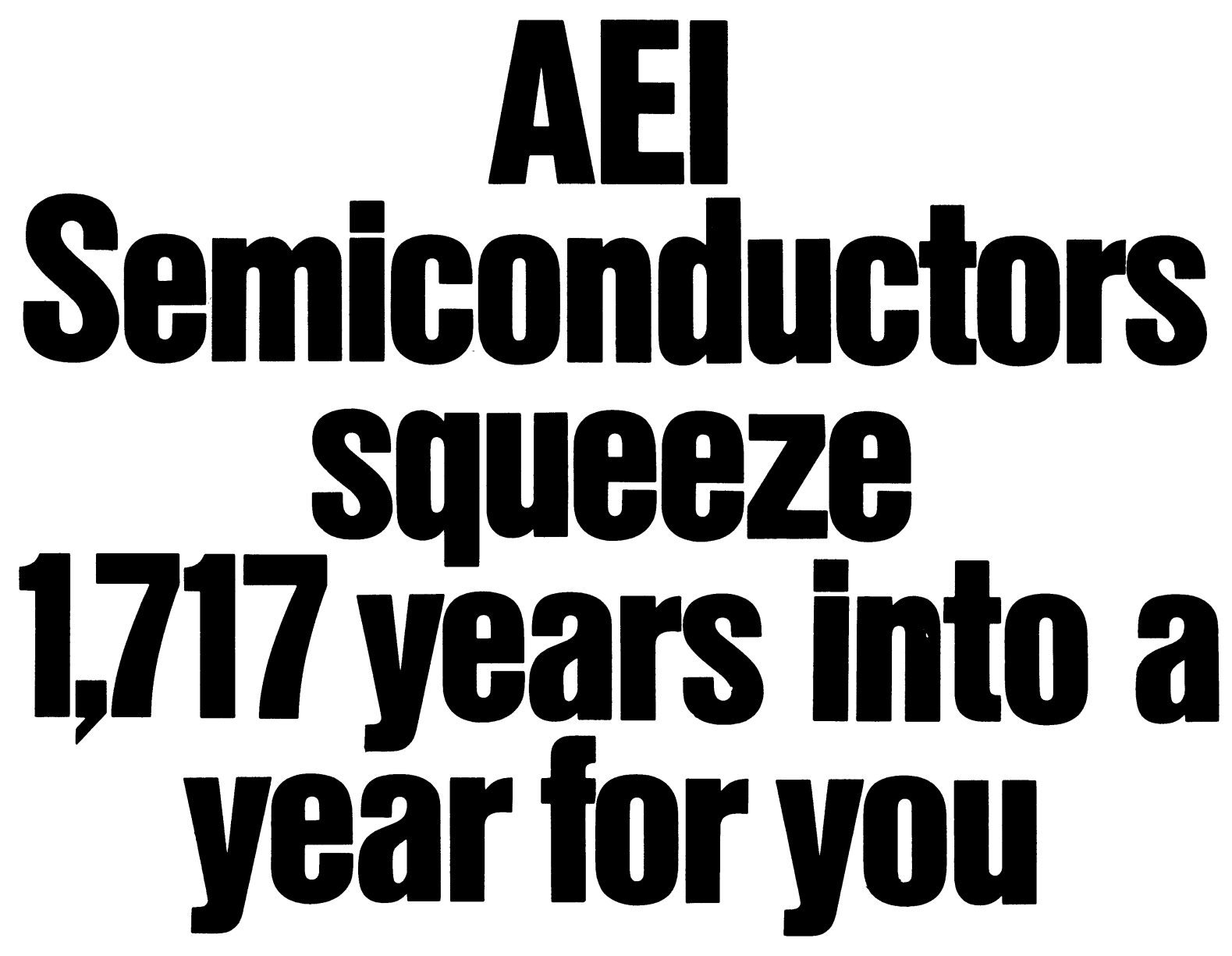

$15,000,000$ device hours per year: that's what AEI Semiconductors spend on reliability testing.

These are the devices: point contact diodes, gold bonded diodes, planar diodes, reference diodes and rectifier diodes, thyristors and triacs, integrated assemblies and modules.

And all devices supplied to you are subject to BS 9300 type quality and inspection.

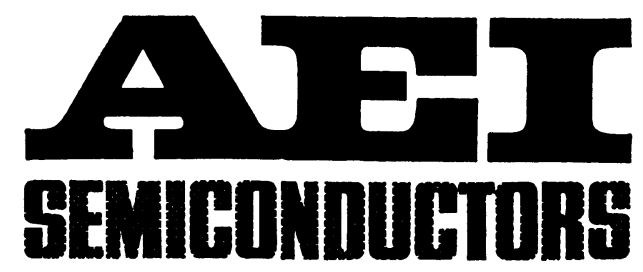

AEI Semiconductors Limited, Carholme Road, Lincoln. Telephone : Lincoln 29992. 


\section{Component Reliability}

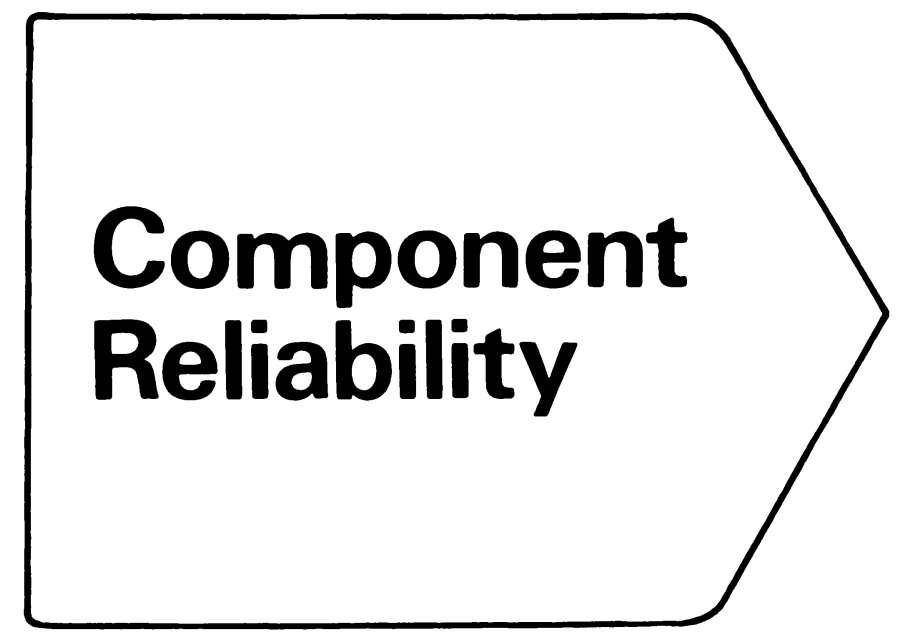

Edited by William $F$ Waller

AMITPP AssIRefEng

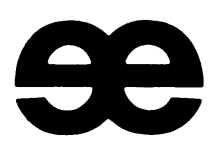

\section{Macmillan Engineering Evaluations}

Published by

The Macmillan Press Limited

Technical and Industrial Publishing Unit

Managing Editor William F Waller

AMITPP AssIRefEng

Advertisement Representative Alan Kay

General Manager Barry Gibbs

The Macmillan Press Limited

Brunel Road Basingstoke Hampshire UK

Price $\mathbf{£ 3 . 5 0}$

ISBN 978-1-349-01187-2 ISBN 978-1-349-01185-8 (eBook) DOI 10.1007/978-1-349-01185-8

(C) The Macmillan Press Limited 1971

Softcover reprint of the hardcover 1 st edition 1971978-0-333-12540-3

SBN 333125401 
This book has been published in response to the ever increasing interest in the reliability of electronic components and equipments. In order to present an integrated view of the subject both component manufacturers and users have contributed to the editorial content.

The first three chapters deal with vital introductory subjects and outline terminology, the link between terminology and mathematical expressions and the thinking behind a new quality assurance system. Chapter 1 stresses the importance of correct terminology and the standardisation of terms when discussing failure modes, causes and periods.

Chapters 4-12 inclusive deal with specific electronic components split by generic type and treated from the viewpoint of the component manufacturer. Each chapter considers such factors as design characteristics and their bearing on reliability, the choice of a suitable production technology, the economics of the manufacturing process, component availability and reliability characteristics. Where it is applicable information on trends in component manufacture which will influence the operation of the device is given.

The mathematics of system reliability forms the subject matter of Chapter 13 and provides a lead into the next four chapters which are evaluations of components used for particular equipment areas. These chapters cover the domestic consumer market, defence electronics, commercial radio and computers. They deal with aspects of compatibility, price, availability, standardisation and performance requirements.

Chapters 18, 19 and 20 cover the special requirements of equipments operating in particular environments. They evaluate the needs imposed by extremes of climate, severe variations of pressure and large magnitudes of mechanical shock.

Throughout the book the forthcoming metrication of industry has been a consideration and the majority of data are presented in SI units. However, flexibility has also been a factor and a number of non-preferred SI units are used and, occasionally, where it is felt the subject warrants it, British units are used and an SI conversion factor given.
Chapter 1

\section{Reliability Terminology}

F G Barnes MA CEng MIERE

Mr Barnes is a member of the staff of the

British Standards Institution

Chapter 2 page

\section{Mathematical Expressions of Reliability}

T A Wesolowski Low BSc(Eng)

Reliability Group Leader

Central Electricity Research Laboratories

Chapter 3

page

\section{Quality Assurance System}

\section{A G Manson}

Group Standards Co-ordinator

The Plessey Company Limited

Components Group

Chapter 4

page

\section{Capacitors}

A T Pitt BSc(Hons)

Chief Chemist

Dubilier Limited

Chapter 5

page

\section{Resistors}

B C Roberts $M A$

Electrical Research Association

Chapter 6

\section{Coils and Transformers}

A Porter CEng MIEE

Technical Manager

Whiteley Electrical Radio Company Limited

Chapter 7

\section{Relays and Contacts}

\author{
D S Knights \\ Engineering Manager \\ B \& R Relays Limited
}




\section{Electronic Tubes}

R E B Wyke CEng FIEE FIEI

Quality Controller

GEC Electronic Tubes

The M-O Valve Company Limited

Chapter 9

page 65

\section{Printed Circuit Boards}

A A Ward

Head of Quality Control Laboratory

The MEL Equipment Company Limited

Chapter 10

page 75

Semiconductors and Integrated Circuits

H C Bate $B S C$

Reliability Engineer

Mullard Southampton

Chapter 11

page

83

\section{Connectors}

R T Lovelock FIEE

Technical Director

Belling and Lee Limited

Chapter 12

page

91

\section{Thin Film Circuits}

W Holt BSc ARCS

Technical Manager

The Plessey Company Limited

Microelectronics Division

Chapter 13

page

99

\section{Aspects of System Reliability}

T A Wesolowski Low BSc(Eng)

Reliability Group Leader

Central Electricity Research Laboratories

Chapter 14

page 109

\section{Consumer Entertainment Industry}

\section{E Spielberg $B S C$}

Manager, Components Engineering

Rank Bush Murphy Limited
Chapter 20

page 153

\section{Defence Electronic Equipment}

W P Cole $B S c A$ Inst $P$ and

J R T Low CEng MIEE

Company Quality Manager and

Head of Environmental Engineering

Marconi Space and Defence Systems Limited

Chapter 16

page 125

\section{Commercial Radio Communications}

I G Gourlay

Deputy Chief Engineer Fixed Equipment Laboratory

Pye Telecommunications Limited

Chapter 17

page 135

\section{Computer Equipment}

L Knight MIEE

Manager Quality and Reliability Services

Systems Group Quality Assurance

International Computers Limited

Chapter 18

page 143

\section{Geographical Environments}

L Rhodes CEng MIMechE

Head of Component Reliability and Measurement Group

Signals Research Development Establishment

Chapter 19

page 147

\section{High Altitude \& Varying Pressure Areas}

R G MacKay CEng MIERE

Assistant Chief Electronics Engineer Space Division

Hawker Siddeley Dynamics Limited

Mechanical Shock Areas

J Harris CEng MIERE

Engineering Manager

Decca Radar Limited

Product Guide

page 161

Glossary of Terms

page 169 